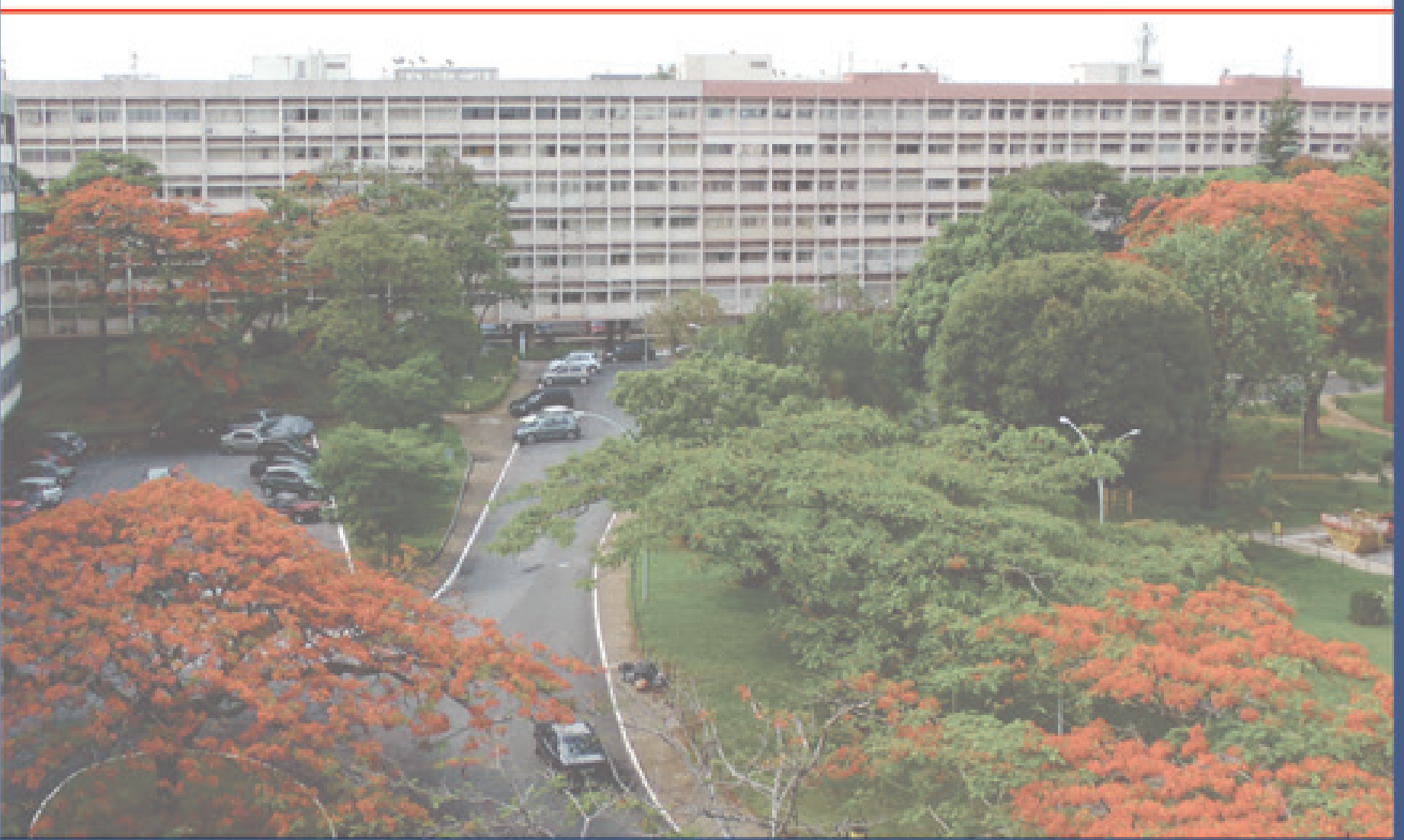




\title{
RESENHA
}

\section{Pressupostos materialistas em dialética do concreto: para pensar cidades e patrimonialização}

Materialist ideas in dialectic of concrete: thinking cities and heritagezation

\author{
Everaldo Batista da Costa ${ }^{1}$ \\ Gilvan Cerqueira de Araújo \\ Rafael Fabrício de Oliveira ${ }^{3}$ \\ Rúbia de Paula Rúbio ${ }^{4}$ \\ Janaína Mourão Freire ${ }^{5}$
}

Resenha e debate com:

KOSÍk, Karel. Dialética do concreto. Trad. Célia Neves e Alderico Toríbio. Rio de Janeiro: Paz e Terra, 1976. 249 p.

A publicação do presente trabalho dá ênfase à importância do debate teórico-metodológico e epistemológico no contexto geográfico, em um momento de crise paradigmática enaltecedora de um pragmatismo tacanho e faceiro que acomete as ciências em geral. No âmbito geográfico, abundam em revistas nacionais e internacionais publicações destinadas a revelar o que se diz resultados de pesquisas comprometidas com o desvendamento das contradições socioespaciais. Entende-

1 Coordenador do Grupo de Pesquisas CNPq Cidades e Patrimonialização (GECIPA). Professor doutor dos Programas de Pós-Graduação em Geografia e em Turismo da UnB.

2 Integrante do Grupo de Pesquisas CNPq Cidades e Patrimonialização (GECIPA). Discente do PPGG-UNESP.

3 Integrante do Grupo de Pesquisas CNPq Cidades e Patrimonialização (GECIPA). Discente do PPGG-UnB.

4 Integrante do Grupo de Pesquisas CNPq Cidades e Patrimonialização (GECIPA). Discente do PPGG-UnB.

5 Integrante do Grupo de Pesquisas CNPq Cidades e Patrimonialização (GECIPA). Discente do PPGG-UnB. 
-se que muito do que é produzido, sobretudo em teses e dissertações defendidas, depois publicadas, carecem de verdadeiro amadurecimento ou aprofundamento teórico e epistemológico. A crise se dá não diretamente pelo novo tempo da produção acadêmica, o qual se redimensionou de fato, no decorrer das últimas três décadas, dadas as facilidades informacionais de circulação e acesso aos acervos, às fontes e para a elaboração concreta do trabalho; esta crise advém, sim, de um descompromisso intelectivo generalizado com a produção do conhecimento original; crise fomentada pela ideologia numérica ou formal das publicações.

Martin Heidegger, em Introdução à Filosofia, é referencial e categórico ao dizer que a ciência passa por três crises: a) a crise em sua estrutura essencial interna; b) a crise no tocante à sua posição no todo de nosso ser-aí histórico social; c) a crise na relação do indivíduo com a própria ciência. $\mathrm{O}$ autor considera que, após a 2a Guerra Mundial, ocorre a difusão do lema da revolução da ciência; é o movimento da antiga ciência acadêmica para uma nova: fica latente uma percepção de paralisia, que foi o prelúdio à profunda especialização científica (que escondia a impotência de transmitir simples e diretamente comunicação com a existência, o conteúdo ontológico primário e originário da ciência). Para Martin Heidegger, rompe-se a conexão entre ciência e um ideal eficaz de formação (ou forças de formação), quando o ideal clássico de formação trazia o homem centrado ante as forças da natureza e a religiosidade cristã (a própria igreja perde o poder total do conhecimento). A crise é instalada! A formação do povo surge como pretexto e ocasião de se tirar vantagens, o que leva à popularização científica, com os "eruditos trabalhando mais e mais em manuais e coletâneas de quarta categoria". A resultante é o esfacelamento interno da ciência, em diferentes dimensões, seguido da perda de seu significado original, que era o de formação nas bases, e a sua falha decorrente.

Logo, mais que uma publicação a seguir os preceitos produtivistas de nossas agências de fomento que, de maneira vertical, impõe aos pesquisadores nacionais um quantitativo de fazeres [mascarado pelo discurso do qualitativo], este trabalho revela a preocupação de um jovem Grupo de Pesquisa que se dedica ao debate sobre cidades e patrimonialização, no Departamento de Geografia da Universidade de Brasília. Este projeto nasceu com um fim específico: valorizar o amadurecimento científico em grupo, com orientandos de pós-graduação, a partir de obras de cunho teórico-metodológico e filosófico particulares, que tragam o debate de método nos vieses materialista, existencialista e fenomenológico. O primeiro texto que este grupo se dedicou, em diversas reuniões, em meses que transpassaram os anos de 2012-2013 é Dialética do Concreto, de Karel Kosík, filósofo tcheco nascido em Praga, em 1926. $\mathrm{Na}$ análise de todo o volume (nos quatro capítulos que constituem um todo coeren- 
te) encontra-se a resposta para o problema: que é a práxis, a relação entre trabalho, consciência e economia, no marxismo? Este é o primeiro trabalho de uma série que virá, lenta e gradualmente, ao longo das décadas que o presente Grupo pretende se reunir para debater obras referenciais das correntes filosóficas anunciadas, reconhecendo o trâmite de futuras dissidências e agregações de integrantes. Assim, este trabalho inaugura uma proposta que se quer diferenciada no tocante ao compromisso com a política acadêmica e, especialmente, com a teoria e os métodos em Geografia.

Na primeira parte do livro, Dialética da Totalidade Concreta, Karel Kosík problematiza as noções de concreticidade e pseudoconcreticidade, atinentes à manifestação da essência da realidade e o seu ocultamento, respectivamente. No âmbito de sua teoria filosófica, o autor defende a possibilidade de encontro da "coisa em si", ou seja, da "estrutura da coisa", quando "o conceito da coisa é compreensão da coisa, e compreender a coisa significa conhecer-lhe a estrutura". A decomposição do que trata por "totalidade estrutural" para se chegar à essência fenomênica da multiplicidade fática do mundo ocorre no uso, entendimento e aprofundamento da postura e exercício da práxis revolucionária na destruição do pseudoconcreto e chegando à autêntica realidade. Nessa leitura, o autor deixa subsídios filosóficos para a distinção metodológica entre o fato cidade e o fenômeno urbanização, por exemplo, quando o primeiro nos remete à coisa material fatídica, o segundo, ao exemplar do processo histórico complexo, multifacetado e fugidio, que redundada no primeiro. A "coisa em si" não está à vista, primeiramente, na cidade, mas no escrutínio da urbanização processual, hoje generalizada. É bom lembrar que K. Kosík não trata de cidades ou da urbanização; esta correlação entre este objeto geográfico e a filosofia do autor advém de uma postura analítica assumida pelo Grupo.

No plano da espiritualidade ou, em outros termos, da cultura, nesta relação de busca pela essência das coisas e da autenticidade do mundo, o autor reintroduz 0 caráter histórico-social da produção da realidade material e imaterial, numa mútua afetação entre o sujeito e o mundo, mas que, por meio da práxis, almeja um sentido objetivo e concreto desta realidade: "É possível, portanto, compreender o sentido objetivo da coisa se o homem cria para si mesmo um sentido correspondente". Aplica-se a análise dialética para se chegar à essência das coisas: "a realidade é interpretada não mediante a redução a algo diverso de si mesma, mas explicando-a com base na própria realidade, mediante o desenvolvimento e a ilustração das suas fases, dos momentos do seu movimento". Essa perspectiva força o reconhecimento da importância da noção de processo e da periodização à leitura geográfica dos fenômenos do mundo. $O$ entendimento da simultaneidade espaço-tempo tem na periodização dos fenômenos o mais eficiente recurso metodológico. 
O autor, ao dizer que o todo é simultaneamente acessível, mas caótico, busca revelar a importância particular do detour na forma de ascensão do abstrato ao concreto. Movendo-se dinamicamente, pela negação da imediatibilidade e na dialética materialista como superação da aparência abstrata, a "coisa" pode se revelar como uma totalidade concreta. De fato, para K. Kosík, totalidade não significa todos os fatos, significa: "realidade como um todo estruturado, dialético, no qual ou do qual um fato qualquer (...) pode vir a ser racionalmente conhecido". Totalidade é a teoria da realidade como concretude. Assumir e apreender a realidade pela concreticidade emoldurada pela estrutura do todo com as partes, pode favorecer e exigir um segundo plano, por meio das metodologias - descrição, compreensão, ilustração e avaliação de seções tematizadas da realidade. O positivismo erradicou a teologia da ciência; paralelamente, reduziu a realidade à matemática e à física, o que induz à crítica sobre os modelos lógicos e seus formalismos incapazes de representar, plenamente, a essência da "coisa". Ao problematizar a emergência de uma ciência ligada à matriz filosófica do positivismo e no primitivo neopositivismo em seu tempo, K. Kosík entende que a reversão deste processo está na busca pela filosofia materialista, que pode respaldar a ciência em termos de estrutura ou sistema (aberto e reconhecedor das contradições do mundo, da feitura dos fatos e do desenrolar dos fenômenos). A realidade é um conjunto de fatos. Cada fato na sua essência ontológica reflete uma realidade. Conhecer a realidade histórica é um processo de apropriação teórica (crítica, interpretativa, de avaliação e validação). O trabalho científico representa um caminho para o conhecimento concreto dos fatos e o desnudamento dos fenômenos. Mas, esse trabalho deve ser incansavelmente ininterrupto, dado o caráter transitivo da própria realidade. Logo, conhecer a realidade, atingir a totalidade absoluta ou concreta significa alcançar uma coisa provisória e não efetiva, devido à mutabilidade permanente do mundo. Essa interpretação leva ao questionamento das pesquisas ditas geográficas, mas que se focam, simplesmente, na operação cartográfica de fatos e negligenciam a concretude dos fenômenos que redundam nesses mesmos fatos. Nesse sentido é que, em reflexão recente sobre a prática socioeconômica do turismo, patenteou-se "a cidade enquanto fato, o urbano enquanto fenômeno junto ao processo de urbanização e o turismo como elemento a posteriori para e da própria análise (...) Metodologicamente, há de se reconhecer que a propalada geografia do turismo deve buscar as bases da geografia enquanto ciência, para o seu amadurecimento, reconhecendo-a como campo do saber voltado ao desvendamento das contradições socioespaciais" (Costa; Araújo Sobrinho, 2013, p. 267).

Nesse aspecto, um fenômeno (como a patrimonialização, a urbanização e seus derivados) pode ser conhecido como momento do todo, quando o real não nos 
oferece um conhecimento definitivo, mas em transmutação; sua essência advém de derivações relativas, desde a implantação de um shopping center em um setor urbano singularizado até o desenvolvimento de um polo tecnológico em alguma cidade particular. A "compreensão dialética da totalidade significa não só que as partes se encontram em relação de interna interação e conexão entre si e com o todo, mas também que o todo não pode ser petrificado na abstração situada por cima das partes, visto que o todo se cria a si mesmo na interação das partes". Em suma, na primeira parte do livro, K. Kosík define a totalidade concreta; parte de uma concepção dialético-materialista do conhecimento da realidade, que significaria um processo indivisível, cujos momentos para alcança-la são: (a) a destruição da pseudoconcreticidade (fetiche e aparente objetividade do fenômeno), por meio do conhecimento da sua autêntica objetividade; (b) o conhecimento do caráter histórico do fenômeno (fato e contexto, dialeticamente); (c) o conhecimento objetivo e associado ao significado do fenômeno; (d) a totalidade concreta enquanto criação social do homem.

Na segunda parte do livro, Economia e Filosofia, o autor afirma que a investigação que parte do pressuposto de já se ter a essência no próprio processo investigativo, torna-se vazia de sentido. A essência do fenômeno não se imediatiza na investigação ou no objeto. A aparência fenomênica ou as impressões que se formam do objeto estudado, antes do processo profundo de busca, contribui para descortinar a realidade, quando o próprio indivíduo já é em uma realidade, antes de ser num contexto conceitual, antes de se requerer conceitos explicativos dos fenômenos. Mas, a aparência fenomênica, por si, não traz a realidade em essência. Essas questões induzem à necessidade de se ultrapassar a geografia imediata do mundo, aquela cartografada, localizada e potencializada.

É essencial a afirmação do autor de que "antes mesmo de que a economia se torne objeto de especulação, explicação e interpretação científica, ela já existe para o homem, sob um aspecto determinado". Reforça que o homem representa o que julga ser a realidade, mas, antes, está nela inserido, transformando-a ininterruptamente. Economia e Filosofia, o título desta parte da obra, traz a Filosofia como elemento incorporado na vida do homem; ao passo que a Economia constitui, estruturalmente, a razão que rege a vida material em sociedade, por isso também cultural. Portanto, antes de se realizar uma investigação acerca da Economia, enquanto campo científico ou terreno conceitual, há de se atentar para a sua presença na vida do homem, que possui noções ao seu respeito, e, principalmente, está nela imerso, reproduzindo-se reciproca e contraditoriamente economia-sociedade. 
Esta parte do livro traz subdivisões correlacionadas e que respeitam a noção de movimento histórico: Metafísica da vida cotidiana, Metafísica da ciência e da razão e Metafísica da cultura. Escreve uma filosofia que afirma e que nega a resposta aos problemas do homem, ante a obviedade do aparente expresso na superfície corriqueira da vida cotidiana, no contexto de uma ciência que suscita verdades, no bojo de uma cultura que articula aquilo que é a realidade.

Em Metafísica da vida cotidiana, o autor reflete sobre os conceitos: preocupação, cotidianidade e história. Preocupação refere-se à forma elementar em que a economia se manifesta para o homem a partir do preocupar-se e do despreocupar-se. É por meio da preocupação que o homem se insere no mundo funcional da prática cotidiana. Preocupação é a práxis humana onde se desvela o mundo do trabalho e residem as alienações. Para além do sentido usual, no qual se refere a indivíduos abarrotados de funções inquietantes, é a coisificação habitual da práxis humana. A cotidianidade refere-se ao momento do existir. Toda existência possui uma temporalidade que, embora não conjecturada no momento em que se vive, é posteriormente examinada enquanto história. Na definição de K. Kosík, "a cotidianidade é o mundo fenomênico em que a realidade se manifesta de certo modo e, ao mesmo tempo, se esconde". Na transformação da história, a cotidianidade é permanente, pois o viver é instintivo e natural. A cotidianidade guarda, em mutação, a essência da realidade histórica. Está no cotidiano da cidade a história da sociedade urbana, em plena e permanente mutação catalisada pelas forças materiais e existenciais que regem o mundo.

Na Metafísica da ciência e da razão, o filósofo trata a pseudoconcreticidade construída no interior das relações sociais capitalistas. Considera que a racionalidade produzida pela ciência econômica opera a objetivação do sujeito, ou seja, a transformação de todas as ações e características que não estão relacionadas com a objetividade econômica do indivíduo, em variáveis irrelevantes. Por meio da racionalidade econômica produzida pela ciência da economia política, o homem é visto como engrenagem do sistema econômico que aparece como um todo supra-individual, regido por leis gerais. Mesmo que o homem econômico não possa existir fora do sistema, ele não se enxerga como participante ativo do processo produtivo. Para K. Kosík, esta racionalidade produz a realidade reificada, falsa, pois se desenvolve sobre uma irracionalidade gestada no pensamento econômico clássico, a qual desconsidera a historicidade do indivíduo e é incapaz de ir além das relações que este estabelece com o sistema; torna absolutas as leis gerais do capitalismo e produz a pseudoconcreticidade de uma realidade cindida entre o racional e o irracional. Tanto a razão racionalista quanto a razão dialética buscam conhecer a realidade e 
moldá-la; mas, somente a razão dialética se coloca como libertadora, pois não se considera externa à realidade, nem a realidade é vista fora de si mesma.

Finalmente, em Metafísica da cultura, K. Kosík discorre sobre a necessidade de entender a economia e sua amplitude de significação integrada à vida cotidiana. Ressalta que o entendimento da economia, ainda em seu sentido amplo, tem se dado de forma distorcida, a qual ele chama de "fé no fator econômico". Entender a economia como um fator deixa margem para que aquilo que se entende como pertencente a esse fator sobreponha outros fatores criados ao entendimento da realidade, tal como a cultura ou a arte sendo sobrepostas pelo que se chama de economia. Diferente disso, o autor destaca que é preciso entender os conceitos para além da sua pseudoconcreticidade, pois sobre eles há impressões e representações criadas, sentidos e significâncias, e são oriundos da metafísica da vida cotidiana, construídos através de uma metafísica da ciência e da razão, e que não podem estar destituídos de uma metafísica da cultura. Os conceitos tornam-se, assim, produtos históricos e vinculados a uma totalidade mais ampla. Tais questões favorecem a indagação permanente dos conceitos e das noções em Geografia, sua adaptação ao mundo do presente, que é sempre refeito por revigoramentos políticos, técnicos e ideológicos transvestidos.

Em suma, a segunda parte do livro perpassa questões da metafísica relacionada à estrutura econômica, a partir da tríade vida cotidiana, ciência e razão, e cultura. $\mathrm{Na}$ metafísica da vida cotidiana, dedica-se a entender o homem em sua práxis. $\mathrm{Na}$ metafísica da ciência e da razão, insere o homem em um sistema materialista. Na metafísica da cultura, a realidade social é inseparável dos produtos e das formas da existência. Na totalidade histórica dos produtos sociais, as 'coisas' exteriores feitas pelo homem exprimem o caráter da realidade (natureza) humana, mas também, por sua vez, o criam, simultaneamente.

A terceira parte do livro tem por título Filosofia e Economia e busca o significado total de O Capital de Karl Marx. Para K. Kosík, esta obra é mal interpretada, ao ser analisada aos fragmentos. "A história do texto, em certo sentido, é a história de sua interpretação: todas as épocas e todas as gerações acentuam no texto alguns aspectos, atribuindo-Ihes maior importância que a outros". Em Marx de O Capital, a economia se entrelaça com a sociologia, a filosofia da história e a filosofia, diferentemente de A riqueza das nações, obra puramente econômica, assegura Kosík; entrecruza a ciência (economia) com a filosofia (dialética). Segundo o autor, são notórias quatro avaliações genéricas de O Capital: (a) o texto tem um significado econômico e lógico-metodológico; (b) o texto tem valor de análise econômica da 
sociedade e, ao mesmo tempo, falta a este conteúdo uma verdadeira filosofia capaz de a ele se adaptar: a fenomenologia; (c) o texto traz uma economia política pura, uma análise de mecanismos, ou uma análise existencial econômica com significado metafísico, que ultrapassa o próprio campo da economia; (d) distingue-se no texto a parte especificamente econômica das especulações filosóficas (dialética); protege-se o Marx grande economista do Marx filósofo; "suas análises econômicas são entendidas com base no método científico político-social, que é diferente da dialética e dela completamente independente".

A natureza da realidade é o ponto de partida da estrutura de O Capital, como articulação dialética, e partindo-se dela é possível compreender e explicar tal estrutura, diz Kosík. Em um movimento que vai do fenômeno à essência, K. Marx analisa a forma social mais simples do produto do trabalho - a mercadoria -, primeiro, no seu aspecto fenomênico (como valor de troca), para depois passar ao exame da sua essência: o valor. "Mercadoria, coisa mística e misteriosa, objeto sensível e sensivelmente supra-sensível (...) Mercadoria, forma concreta do produto do trabalho, o concreto econômico mais simples, a forma celular na qual se contem, de modo oculto, não desenvolvido e abstrato, todas as determinações fundamentais da economia capitalista".

Para K. Kosík, O Capital é uma crítica teórica ou uma teoria crítica do capital; não é somente uma descrição das obras objetivas do movimento social do capital e das correspondentes formas de consciência, também investiga a gênese e a configuração do sujeito que efetua a destruição revolucionária do sistema, ou seja, traz os fundamentos da luta de classes. "A economia não é apenas produção de bens materiais: é a totalidade do processo de produção e reprodução do homem como ser humano-social".

Importante anotação deixada por K. Kosík é a de que a filosofia materialista esboça "a última ontologia do homem". Para o autor, Jean Paul Sartre reconhece que o marxismo é o insuperável horizonte espiritual da nossa época, mas esqueceu de acrescentar o marxismo também como ontologia do homem. "Sobre este esquecimento Sartre baseia a legitimidade do existencialismo (ontologia e antropologia existencial) como necessário complemento da filosofia materialista". Pode ser acrescentando que o materialismo histórico e o existencialismo são métodos a serem trabalhados pelo geógrafo de forma imbricada, em nome de uma práxis manipulativa integradora e em prol da geografia como campo do saber e como existência; por vezes, falta à análise da existência humana certa nitidez, ao passar indiferente diante da base material da existência histórica, onde que existência hu- 
mana e situação prática fazem-se elementos entrelaçados da realidade concreta (Costa; Suzuki, 2012).

A constituição do tempo humano como dimensão constitutiva do ser do homem baseia-se no trabalho como ação objetiva. As dimensões do tempo e a temporalidade do homem são baseadas na objetivação. Sem objetivação não há suspensão temporal (diferenciação de temporalidade em Marx e em Sartre, no materialismo e no existencialismo). Para K. Kosík, tempo e espaço, respectivamente, temporalização e função extensiva, são dimensões essenciais da existência humana, formas específicas do movimento do homem no mundo. Ante a temporalização e a extensão surge a consciência que se externaliza nos objetos através do trabalho. "A existência de criações objetivadas é pressuposto da história, isto é, da continuidade da existência humana".

A quarta e última parte da obra de Karel Kosík denomina-se Práxis e Totalidade; busca a essência destas duas noções no seio da filosofia materialista, de maneira que a primeira é a principal noção desta mesma filosofia. $\mathrm{O}$ autor é taxativo ao reconhecer que a problemática da práxis na filosofia materialista não se apoia na distinção de dois campos da atividade humana (teoria-prática), pois "ela nasce como resposta filosófica ao problema filosófico: quem é o homem, o que é a sociedade humano-social, e como é criada esta sociedade?". Por meio do entendimento da práxis, enquanto esfera do ser humano, que se encontra algo essencial: a própria verdade, pois não é ela "mero símbolo de qualquer outra coisa, mas possui uma importância ontológica". A práxis do homem não retrata prática humana contraposta à teoria; é a própria determinação da existência humana que cunha a realidade; "a práxis é ativa, é atividade que se produz historicamente, unidade do homem e do mundo, da matéria e do espírito, de sujeito e objeto, do produto e da produtividade".

A práxis compreende o momento laborativo e o momento existencial e ambos só são possíveis pela tridimensionalidade do tempo em passado-presente-futuro. Por isso, K. Kosík deixa claro que a práxis se manifesta tanto na atividade objetiva do homem que humaniza a natureza, como na formação da subjetividade humana, na qual os momentos existenciais (medo, angústia, náusea, alegria, riso, esperança) não se apresentam como experiência passiva ou estanque, mas como parte de uma infindável luta pelo processo da realização da liberdade humana. "Sem o momento existencial, a práxis se degrada ao nível da técnica e da manipulação". Nesse sentido, a Geografia deve se aprofundar na dialética de recíproca determinação que há entre a liberdade individual existencial e o condicionamento total das particularidades que reproduzem o espaço. 
No pressuposto materialista, a práxis traz e revela o universo e a realidade em sua essência, uma vez que a teoria pura, o único caminho aberto ao homem para o conhecimento do mundo na totalidade, onde a prática cotidiana visual busca modificar, não tem condições de intuir a totalidade do mundo. "A práxis é a abertura do homem diante da realidade e do ser". Na práxis o homem situa-se, reproduz e reconhece o mundo como totalidade, revisita sua finitude e se coloca em contato com essa totalidade. Para K. Kosík, “o homem não é apenas uma parte da totalidade do mundo: sem o homem como parte da realidade e sem o seu conhecimento como parte da realidade, a realidade e o seu conhecimento não passam de mero fragmento". À totalidade do mundo corresponde também o modo pelo qual a realidade se abre ao homem e o modo pelo qual o homem descobre esta totalidade. "À totalidade do mundo pertence também o homem com a sua relação de ser finito com o infinito e com a sua abertura diante do ser, sobre as quais se baseia a possibilidade da linguagem e da poesia, da pesquisa e do saber".

Homem e totalidade perfazem-se mutuamente. A ciência, as técnicas, a cultura, todas as indústrias humanas resultam da natureza humanizada e das coisas socializadas, com variações decorrentes na e da história das ações, das intenções. O homem existe e se define pela sua práxis; por ela e com ela reproduz a totalidade mutante. "O homem existe na totalidade do mundo e reproduz espiritualmente a totalidade do mundo".

Assim, K. Kosík finaliza sua obra trazendo a concepção de que a realidade só tem corpo com a totalidade da natureza, da história e do homem, simultânea e não sucessivamente; entender essas totalidades simultâneas pode favorecer atingir a "coisa em si" dos fenômenos do cotidiano, sabendo que "a coisa em si não é uma coisa qualquer e, na verdade, não é nem mesmo uma coisa: a coisa em si de que trata a filosofia é o homem e o seu lugar no universo, ou: a totalidade do mundo revelada pelo homem na história e o homem que existe na totalidade do mundo".

Dialética do Concreto é uma leitura lúcida, didática e profunda do materialismo dialético, no século XX. À Geografia, favorece interpretar os fenômenos espaciais (como a urbanização e a patrimonialização) apontando para o papel revelador da tridimensionalidade do tempo (passado-presente-futuro) correlacionado à práxis, a qual guarda os diferentes sentidos da realidade mimetizada nos momentos do existir e vinculada ao cotidiano. 


\section{Referências}

COSTA, Everaldo B; ARAÚJO SOBRINHO, Fernando. Cidade, urbano e urbanização: fundamentos metodológicos para o estudo do turismo. AZEVEDO, Francisco Fransualdo; et al. (Org.). Turismo em foco. 1ed.Belém: NAEA / CNPq, 2013, v. 1, p. 269-287. COSTA, Everaldo B; SUZUKI, Júlio C. Materialismo histórico e existência: discurso geográfico e utopias. Revista Espaço e Geografia, vol. 15, no 1, 2012, p. 115-147.

HEIDEGGER, Martin. Introdução à filosofia. São Paulo: Martins Fontes, 2009, p. 269. KOSÍk, Karel. Dialética do concreto. Trad. Célia Neves e Alderico Toríbio. Rio de Janeiro: Paz e Terra, 1976. 249 p. 